\title{
Manoeuvring Simulation on the Bridge for Predicting Motion of Real Ships and as Training Tool in Ship Handling Simulators
}

\author{
K. Benedict, M. Kirchhoff, M. Gluch \& S. Fischer \\ Hochschule Wismar University of Technology, Warnemunde, Germany \\ M. Baldauf \\ World Maritime University, Malmo, Sweden
}

\begin{abstract}
International sea transport has growing rapidly during the period of the last decade. Ships became larger and wider and its container capacity is still increasing to $12.000 \mathrm{TEU}$ and even more. To navigate such vessels safely from port to port and specifically within the ports more and more enhanced computerbased systems are installed on the ships navigational bridges. Prediction tools are very helpful and already in use on ships for a long time. However, the simplification of existing predictions allows restricted use only and do not include the immediate response on changes of rudder and engine. Within this paper investigations into the feasibility and user acceptance of newly developed layout of navigation display will be introduced and selected results of simulation studies testing the influence on manoeuvre performance dependent on different kind of prediction functions will be discussed. Examples will be given for results from test trials in the full mission ship handling simulator of the Maritime Simulation Centre Warnemunde and a concept for the application of the developed .tools for purposes of collision avoidance is described.
\end{abstract}

\section{INTRODUCTION}

International sea transport has growing rapidly during the period of the last decade. Ships became larger and wider and its container capacity is still increasing to 12.000 TEU and even more. To navigate such vessels safely from port to port and specifically within the ports from and to the dedicated berths more and more enhanced computer-based systems are installed on the ships navigational bridge to support the pilot, the master and his navigating officers as well.

Investigations are ongoing to integrate features for new manoeuvring and steering equipment such as azimuth propellers or waterjets and in parallel to enhance the predictions of the complex own ship motions taking into account the use of the controls in time.
Prediction tools are very helpful and are already in use on ships for a long time, beginning with trial modes in ARPA radars up to curved headline overlay in ECDIS. However, the simplification of these predictions allows restricted use only based either on estimated future courses \& tracks or on the simple integration of the current ship motion not including the immediate response on changes of rudder and engine.

New concepts for on board displays and simulation tools were developed in research projects funded by the German Federal Ministry of Education and Research together with partners from manufacturers like SAM Electronics Hamburg and INTERSCHALT/AVECS.

A prediction tool was developed to simulate the ships motion with complex dynamic models in fast time and to display the ships track immediately for the intended or actual rudder or engine manoeuvre. 
These simulations are based on input from the ships actual sensors via the Voyage Data Recorder and furthermore from diagnosis tools analysing the status of the manoeuvring facilities and providing information in case of failures, e.g. reduced engine power or larger rudder response time due to malfunctions of the equipment.

This tool can be used both for real ships operation on board but also for the effective training in simulators because of its unique advantage that the consequences of manoeuvring commands can be seen immediately before the ship has even changed her motion.

Within this paper investigations into the feasibility and user acceptance of the new layout of navigation display will be introduced and selected results of simulation studies testing the influence on manoeuvre performance dependent on different kind of prediction functions will be discussed. Examples will be given for results from test trials in the full mission ship handling simulator of the Maritime Simulation Centre Warnemunde.

\section{STATE OF THE ART AND NEW APPROACH}

The role of computer based simulation is increasing on the ships bridge, especially for manoeuvre planning and for collision avoidance. Prediction tools are very helpful and already in use on ships for a long time. Well known is the so called Trial Manoeuvre mode in ARPA radars to be used in order to analyse future encounter situation for selected relevant course and speed alternatives to deck potential collision avoidance strategies.

With the emerging Electronics Chart and Information Systems ECDIS new tools were introduced for supporting voyage planning by means of manoeuvring characteristics. For controlling the ship on her route the future track of the ship was shown as a so called "curved headline" overlay in ECDIS.

However, theses prediction are very simple only based either on new constant course and speed values as in the ARPA trial function or on estimated future courses $\&$ tracks based on the simple integration of the current ship motion parameters as rate of turn and speed components to be considered as constant.

The simplification of these predictions allows restricted use only. That is why new concepts for on board displays and simulation tools were developed using an innovative approach which includes the immediate response on changes of rudder and engine commands for the display of the future track.

This approach was investigated in research projects, dedicated on the one hand to the further development of user interfaces on ships navigational bridges and to investigations into potential improvements for manoeuvring assistance on the other hand.

A prediction tool was developed to simulate the ships motion with complex dynamic models in fast time and to display the ships track immediately for the intended or actual rudder or engine manoeuvre (Benedict, Baldauf et al 2007). Generally there are two areas of application of such a prediction tool. It can be seen both as training tool for ship manoeuvres and to be used as assistance tool on board vessels:

- Training Tool: The prediction of ships motion as an immediate response could be an excellent method to demonstrate the results of changes or alternatives of using manoeuvring control devices as for instance propellers, rudders or thrusters. This is of increasing importance specifically for the growing complexity of manoeuvring control systems starting from simple one-propeller and middle rudder, via twin propellers with double rudder up to new azimuth propellers which can be turned by $360^{\circ}$ (there are ships with even four of these sophisticated thrusters).

- Assistance Tool: Predictions as elements of on board displays can be used as in the loop control elements to steer the ship manually but supported by the future track or speed indication in the ECDIS interface.

One crucial problem for the prediction is the accuracy of the simulation. In the mentioned projects a very sophisticated approach was used to represent the ships' dynamic by very extensive equations very similar to those used in Full Mission ship handling simulators. The parameters of the equation of motion will be estimated by an extra fast time simulation program and a data analyser already used for tuning of the hydrodynamic models in the ship handling simulator. These methods will be described in the following chapters and examples will be given for results from test trials in the full mission ship handling simulator of the Maritime Simulation Centre Warnemuende upgraded in 2007/2008.

This Simulation Centre accommodates six simulators embracing a common network and comprised of four ship-handling bridge systems with differing levels of equipment, a ship's engine system and a VTS simulation facility.

The interaction of many of the single simulators is one of the unique features of the MSCW: they can be interfaced to form a big scenario comprising all simulators and connecting e.g. the big bridge 1 with the full mission engine simulator. (Benedict 2000). 


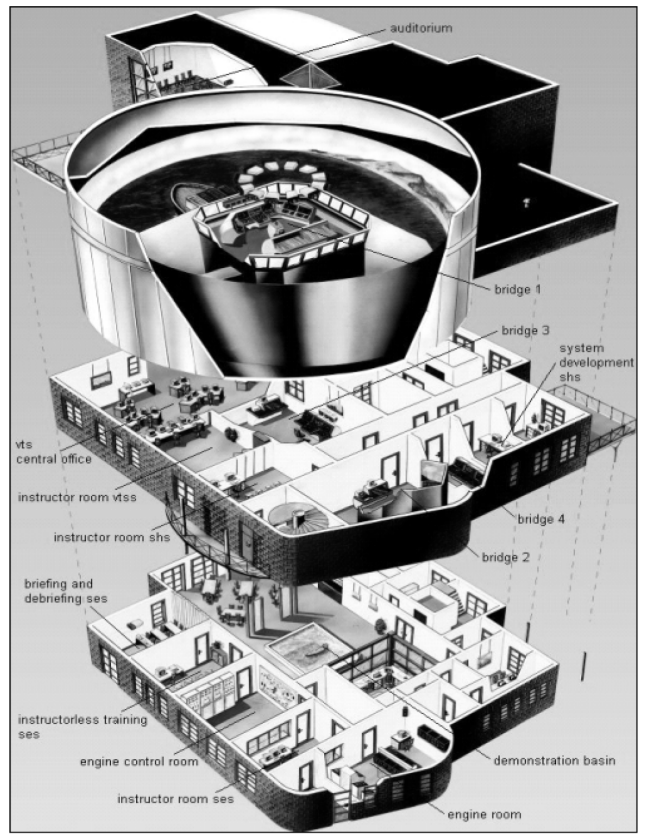

Figure 1: Maritime Simulation Centre at Warnemuende (MSCW) which comprises three interfaced simulator segments for ship handling, ship engine and VTS

\section{APPROACH FOR PREDICTION TOOL}

\subsection{Ship dynamic model and Technological Setup}

The following equation of motion was used as math model for the ships dynamic:

$$
\begin{aligned}
& X=m\left(\dot{u}-r v-x_{G} r^{2}\right) \\
& Y=m\left(\dot{v}+r u+x_{G} \dot{r}\right) \\
& N=I_{z} \dot{r}+m x_{G}(\dot{v}+r u)
\end{aligned}
$$

On the right side are the effects of inertia where $u$ and $\mathrm{v}$ represent the speed components in longitudinal and transverse direction $\mathrm{x}$ and $\mathrm{y}, \mathrm{r}$ is the rate of turn of the ship. The ships mass is $m$ and $x_{G}$ is the distance of centre of gravity from the origin of the co-ordinate system, $\mathrm{I}_{\mathrm{z}}$ is the moment of inertia around the $\mathrm{z}$-axis.

The ships hull forces $\mathrm{X}$ and $\mathrm{Y}$ as well as the yawing moment $\mathrm{N}$ around the $\mathrm{Z}$-axis are on the left side. Their dimensionless coefficients are normally represented by polynomials based on dimensionless parameters, for instance in the equation for transverse force $\mathrm{Y}$ and yaw moment $\mathrm{N}$ given as the sum of terms with linear components $\mathrm{Nr}, \mathrm{Nv}, \mathrm{Yr}$ and $\mathrm{Yv}$ and additional non-linear terms. Other forces as for instance rudder forces and wind forces are expressed as look up tables. There are additional equations for the engine model, where are also look up tables to represent automation systems characteristics. The solution of this set of differential equations is calculated every second; some internal calculations are even done with higher frequency.
The Input output relations are shown in Figure 2. The inputs consist of controls, the states and the data for the environmental conditions in the three blocks on the left side. The core module Simulation/Prediction is in the centre of the figure. Additionally there is an input of the Ships condition parameters. They are normally fixed but in case of malfunctions they might change, e.g. reducing the rudder turning rate or maximum angle. The results from the Simulation block are transferred to be displayed in ECDIS or Radar.

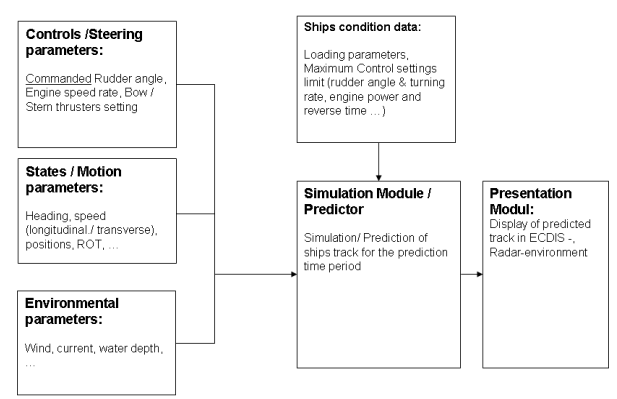

Figure 2. In-/Output concept for prediction process and data flow

In Figure 3 the more technological setup of the structure of modules is described. A commercial IMO-proven Voyage Data Recorder (VDR) plays the role of data collector for the controls, states and environmental parameters measured by the ship sensors.

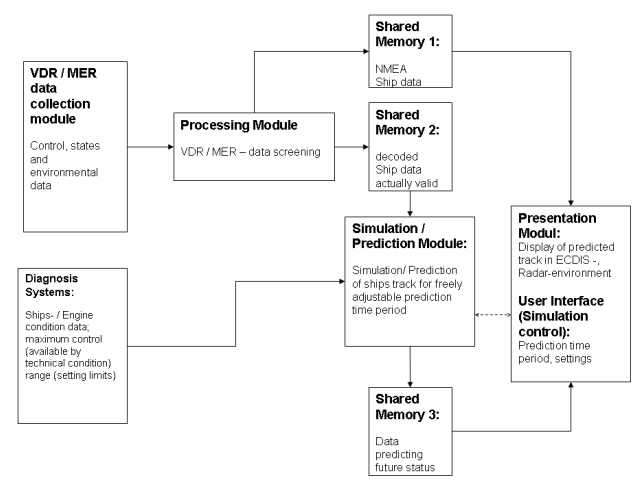

Figure 3. Modules \& data sources and sinks

After pre-processing the data will be stored in Shared Memory 1, together with the condition parameters which will be provided by a diagnosis system. This system continuously checks the ships and engine conditions. From this memory the data are available for other modules:

- The Simulation Prediction Module uses the data from Shared Memory 1 to predict the ships track and speed for a certain time period. The results are sent to Shared Memory 2.

- The Presentation Module uses the data both to display the actual position and from Shared Memory 2 to display the future track.

- The Prediction parameters are controlled by an user interface integrated in the Presentation module with regard to predicting cycle and length of track. 


\subsection{Presentation of dynamic Predictions in ECDIS environment}

For a compact presentation of information to the captain, pilot and responsible navigating officer respectively a new layout of a conning display was designed and implemented into the equipment installed on an integrated navigation system. The display layout contains an overlay of ECDIS and CONNING information together with the prediction (figure 4).

In the centre the ECDIS information in Head up Mode together with motion parameter for longitudinal speed $(10.1 \mathrm{kn}$ and transverse speed $(0.1 \mathrm{kn})$ as well as a circle segment with the rate of turn to STB $((4.0 \% \mathrm{~min})$ is shown. The ships position is displayed in the centre of the ECDIS as ships contour where the track prediction can be indicated as curved track or as chain of contours for the selected prediction time. The prediction parameters as range or interval of presentation can be set in the control window at the right side.

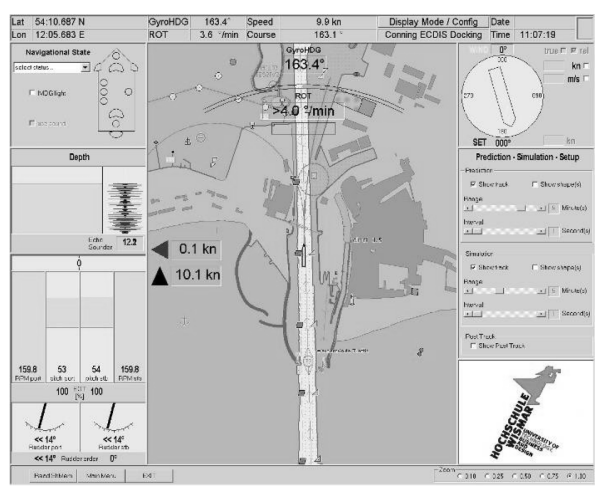

Figure 4. Layout concept for Manoeuvring Prediction in ECDIS

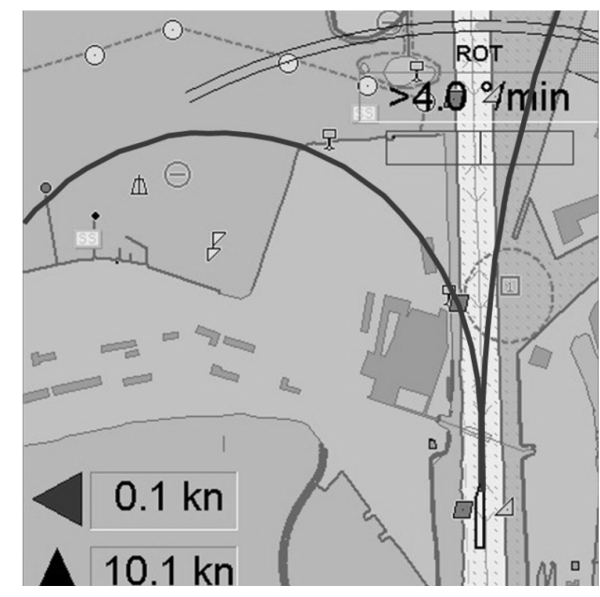

Figure 5. Comparison of methods based on different tracks

In the centre the ECDIS information in Head up Mode together with motion parameter for longitudinal speed (10.1.kn and transverse speed $(0.1 \mathrm{kn})$ as well as a circle segment with the rate of turn to STB $((4.0 \% \mathrm{~min})$ is shown. The ships position is displayed in the centre of the ECDIS as ships contour where the track prediction can be indicated as curved track or as chain of contours for the selected prediction time. The prediction parameters as range or interval of presentation can be set in the control window at the right side.

The predicted track for the simplified prediction is shown as red curve (here shown in black to starboard): According to the actual rate of turn to starboard the conventionally predicted track is presented as a circle segment to the right side as track for the time range of 5 min with a speed of $10.1 \mathrm{kn}$.

The dynamic prediction with the full simulation model is shown as blue curve (here shown in black to port). This dynamic prediction reflects the setting of rudder and propeller parameters shown in the left bottom window: The two rudders of the ferry used in this example are set to $14^{\circ}$ Port and the Engine Order Telegraph for the two controllable pitch propellers are set to $100 \%$ representing $159.8 \mathrm{rpm}$ of the propeller. The actual pitch status is 53 and 54 respectively. This interface allows for a presentation of dynamic predictions of steering and stopping characteristics as an immediate response according to the current steering handle or engine order telegraph position.

\subsection{Investigations into the effects of predictions on ship handling}

For the purpose of testing the potential effects of such enhanced prediction tool it was implemented in the INS equipment of the large full mission simulator bridge of the Ship handling simulator of MSCW.

For trials to test the effects of such a tool on the navigators behaviour a sample of a PanMax container vessel with Loa $=294 \mathrm{~m}$, Boa $=32,2 \mathrm{~m}$, Draft $=12 \mathrm{~m}$ and a Displacement of $74.000 \mathrm{t}$ is used in the simulation experiment. The container vessel is equipped with one fixed propeller and one balanced rudder blade. Additionally one bow thrusters is available for manoeuvring the ship.

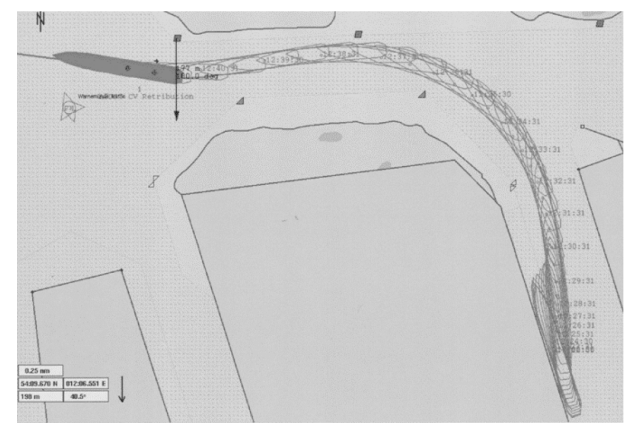

Figure 6: sample of a result from experimental trial to investigate effects of predictions tool

A first basic test scenario was developed and implemented. The task is to steer a vessel from a berth into a fairway to leave a harbour area. The scenario is used for trials with participants who are not familiar with the selected ship. The task to be performed is to safely manoeuvre the ship into the fairway. Each participant started with a trial to become famil- 
iar with the ships behaviour and without using the prediction tool. The second run of the test contains the same task but were performed in another area of the port. An example of a trial using the prediction tool is given in the following figure.

After the first series of simulation runs there are already some tendencies regarding the effects that can clearly be identified.

- There are successful manoeuvres, when the predictor was used; even if the test person has no experiences for the specific ship and the area.

- The execution time for the manoeuvre is smaller when the predictor is used.

- The number of orders (for engine, thrusters and rudder) decreases with the use of the predictor.

To proof these tendencies the trials will be continued with cadets during the next semesters. Then more detailed investigations with more detailed statistical analysis will be performed.

\section{APPLICATION OF THE PREDICTION MODULES FOR ON BOARD COLLISION AVOIDANCE}

The prediction algorithm and the technical setup is planned to support pilots, captains and navigating officers when manoeuvring a ship in narrow waters, moreover it also may be applied for the improvement of the on board collision avoidance process. There are ongoing investigations to enhance the existing collision warnings by using predicted manoeuvring characteristic data for adaptation of alarm thresholds in contrary to conventional CPA/TCPA calculations and fixed limit values to be applied to every encounter situation without any distinction of the prevailing circumstances of the encounters

Core element of this new approach is the risk model for situation assessment (Hilgert, Baldauf 1996) differing between the three types of encounter situations and additionally taking into account the two conditions of visibility as laid down in the International Rules for Preventing Collisions at Sea as well. Furthermore the concept is also applied to the new IMO's definition given in the new performance standards for INS (IMO, (2007) and allows for introducing situation dependent collision alert categories "Caution", "Warning" and "Alarm" as well. Cautions and warnings may be switched off by the operator, but alarms may not.

For self adaptation of thresholds different CPA limits are foreseen, which will be set automatically according to the hydrodynamic safe passing distance related to the dimensions of the involved ships, the actual sea area and visibility conditions as well.
As suggestion for initial basic values CPA limits were determined by detailed field study. To ensure a wide range of user acceptance one emphasis was laid on the navigators' behaviour and taken into account. From the point of view of well experienced navigators it is rather more practical to determine the safe passing distance with respect to usual data. Under pragmatic aspects and according to the investigations performed it can be assumed that the nominal safe passing distance have to be in relation to the ship's length of the largest vessel $\mathrm{L}_{\max }$ involved in an encounter situation ( $\mathrm{L}_{\max }$ should not be less than 1 cbl). Taking into account the different types of encounter situations as defined in the COLREGs a factor " $f_{x}$ " is necessary which depends on the kind of situation " $\mathrm{x}$ " and the can be determined by Safe Passing Distance (nominal) $=\mathrm{f}_{\mathrm{x}} \cdot \mathrm{L}_{\max }$ )

The values, given in Table 1, are derived from several investigations (see i.a. Baldauf (2004)) and are suggested for the four main types of encounter situations.

Table 1. Recommendation for basic values to calculate situation dependent threshold

\begin{tabular}{lcc}
\hline $\begin{array}{l}\text { kind of encounter } \\
\text { situation }\end{array}$ & $\begin{array}{c}\mathrm{f}_{\mathrm{x}} \\
\text { (good visibility) }\end{array}$ & $\begin{array}{c}\mathrm{f}_{\mathrm{x}} \\
\text { (restricted visibility) }\end{array}$ \\
\hline $\begin{array}{l}\text { head-on situation } \\
\text { meeting port/port-side } \\
\text { overtaking }\end{array}$ & 2.5 & 5 \\
$\begin{array}{l}\text { head-on situation } \\
\text { meeting stb/stb } \\
\text { crossing situation }\end{array}$ & 2.5 & 5 \\
\hline
\end{tabular}

These values were proved by simulation studies and are valid under the conditions "open sea" for good (column 2) and restricted visibility (column 3). These values have to be applied to the actual encounter situations.

Table 2. Response times for turning manoeuvre depending on own ships speed and rudder angles

\begin{tabular}{lccc}
\hline $\begin{array}{l}\text { Own } \\
\text { speed } \\
(\mathrm{kt})\end{array}$ & $\begin{array}{l}\text { Rudder } \\
\text { angle }\left(^{\circ}\right)\end{array}$ & $\begin{array}{l}\text { time for course } \\
\text { alteration of } \\
90^{\circ} \mathrm{t}_{90^{\circ}}(\mathrm{min})\end{array}$ & $\begin{array}{l}\text { covered } \\
\text { distance } \mathrm{t}_{90^{\circ}} \\
\mathrm{d}_{\mathrm{OS}}(\mathrm{nm})\end{array}$ \\
\hline 24 & $\begin{array}{l}\text { hard a- } \\
\text { starboard } \\
\text { starboard } \\
15\end{array}$ & $2: 25 \mathrm{~min}$ & 0,97 \\
24 & $\begin{array}{c}15 \\
\text { starboard } \\
20\end{array}$ & $3: 24 \mathrm{~min}$ & 1,54 \\
22 & $\begin{array}{c}20 \\
\text { starboard } \\
15\end{array}$ & $4: 10 \mathrm{~min}$ & 1,25 \\
22 & & 1,53 \\
\hline
\end{tabular}

With respect to the technical setup for predictions described above manoeuvring data, especially the response time for a potential course change of $90^{\circ}$, may be taken from extracted processed VDR recordings and used for automatic adaptation of the TCPA related limits of the dangerous target alarms, either by taking them directly from a database or by calcu- 
lations using the fast time simulation algorithms. The response time for turning manoeuvre is a fundamental value to avoid a collision. Such response times are only available to captains on board for some standard manoeuvres under selected environmental and loading conditions as well and they are usually neither exactly known nor applicable to the prevailing circumstances of a concrete dangerous situation to be solved. A sample of a standard set of response times for a usual sized 5.000 TEUs container vessel is given in Table 2.

As stated before, when applying the drafted concept for situation dependent alarm thresholds those values should be determined by means of the manoeuvring prediction module. The principal application's structure and the relevant data flows are given in the figure below.

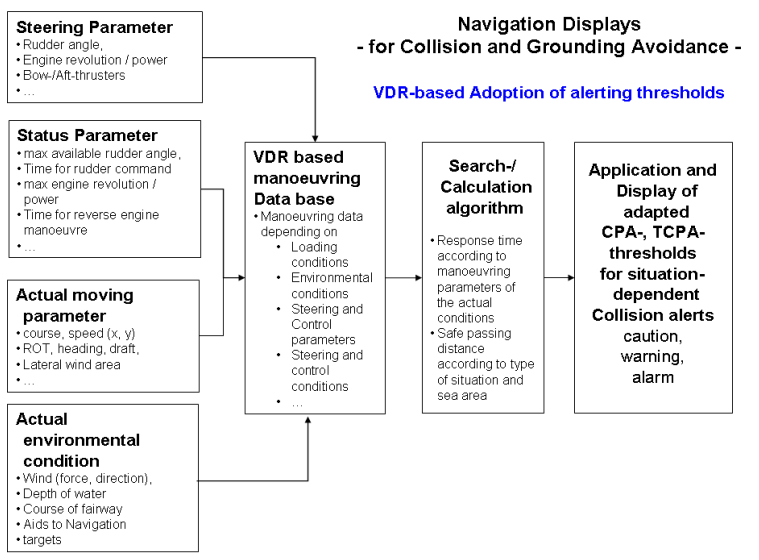

Figure 7: Principal application structure and data flow for selfadaptation of thresholds for collision alerts

First studies applying the situation dependent thresholds for detection of dangerous encounter situations in overall traffic scenarios in sea areas off the coast monitored by VTS resulted in a reduction of the number of collision alerts by $40 \%$.

\section{SUMMARY}

A prototype software module for an On-line Manoeuvring Assistance is developed based on a prediction tool using advanced simulation technology on board of ships. The results of rudder and engine control changes will be immediately displayed in an Electronic chart environment to be used for manual correcting steering actions. The system was tested using the excellent resources for research and development of the Maritime Simulation Centre Warnemunde and can be used also as a training tool in student courses. During test trials several manoeuvring situations were managed with an increased performance when using the prediction tool. A concept for the application of the tools for purposes of collision avoidance is developed in order to reduce the number of alarms.

\section{ACKNOWLEDGEMENTS}

The research results presented in this paper were partly achieved in the research project Conditionbased navigational displays (ZUMANZ) belonging to the "Maritime Safety Assistance Rostock" consortia funded by the German Federal Ministry of Education and Research and surveyed by Research Centre Jülich as well as under the European MarNIS project, funded by the European Commission, Department for Energy and Transport.

\section{REFERENCES}

Benedict, Kirchhoff, Baldauf, Gluch, Fischer, KO (2007), Concept for On-board Prediction Displays based on actual Ship Condition and Manoeuvring Simulation for Navigation and Shiphandling. Paper at IMSF Conference 2007, August 20 - 242007 Busan / Korea

Baldauf, M.; Benedict, K.; Fischer, S.; Gluch, M.; Kirchhoff, M.: DE (2007) Navigation Displays for Ships with simulation based Predictions. (German) in Rötting et al (Eds.): Prospektive Gestaltung von Mensch-Technik-Interaktion. Fortschr.-Ber. VDI Reihe 22 Nr. 25, Düsseldorf: VDIVerlag 2007, ISBN 978-3-18-302522-0

Baldauf, Benedict, Wilske, Grundevik, Klepsvik, POL (2007), Combination of Navigational Equipment and VDR Based Information to Enhance Alert Management. in Weintrit, A. (Ed.): Advances in Marine Navigation and Safety of Transportation. Monograph Gdynia Maritime University (Poland) and The Nautical Institute London (UK), Gdynia, June 2007, ISBN 978-83-7421-018-8

Baldauf, M. (2004), Enhanced Warning Functions for on board Collision Avoidance using AIS and VDR information, In: R. Dauer, A. de la Pena, J. Puig (eds): International Congress on Maritime Technological Innovations and Research - Proceedings. SCI UPC, Barcelona, ISBN 84-7653-861-8

Oltmann, JP (2003), Identification of Hydrodynamic Damping Derivatives - a Pragmatic Approach, MARSIM - International Conference on Marine Simulation and Ship Manoeuvrability, Kanazawa, Japan, August 25th - 28th

Benedict, Baldauf, Felsenstein, Kirchhoff, JP (2003), Computer-based support for the evaluation of ship handling simulator exercise results, MARSIM - International Conference on Marine Simulation and Ship Manoeuvrability, Kanazawa, Japan, August 25th - 28th

Benedict, US (2000), Integrated Operation of Bridge-, Engine Room- and VTS-Simulators in the Maritime Simulation Centre Warnemünde, Conference on Simulation CAORF / JSACC 2000, New York, 3-7 July 2000, Proceedings Vol. 1

Benedict, K. et al: (2006) Combining Fast-Time Simulation and Automatic Assessment for Tuning of Simulator Ship Models. MARSIM - International Conference on Marine Simulation and Ship Manoeuvrability, Terschelling, Netherlands, June 25th - 30th Proceedings, M-Paper 19 p. 1-9

Clarke, Horn, UK (1997), Estimation of Hydrodynamic Derivatives, Proceedings of the 11th Ship Control Systems Symposium, Southampton, Vol. 3, pp. 275-289

Hilgert, H.; Baldauf, M. (1996), A common risk model for the assessment of encounter situations onboard ships. in: Maritime Collision and Prevention, Chiavari Publishing, Surrey, England. 1996, ISBN 0952059223

Clarke, Gedling, Hine, UK (1983), The Application of Manoeuvring Criteria in Hull Design Using Linear Theory, Transactions of the RINA, London,

IMO 2007. Revised performance standards for integrated navigation systems (INS). MSC.252(83). London: IMO 